\title{
Sapajus apella as a model for the development of novel therapeutic approaches for Parkinson's disease
}

\section{Sapajus apella como modelo para o desenvolvimento de novas abordagens terapêuticas para a doença de Parkinson}

\author{
José Augusto Carneiro Pereira Muniz ${ }^{(1 D}$, Leon Claudio Pinheiro Leal1,2 (iD, Carlomagno Pacheco Bahia² (iD), Lane Viana \\ Krejcová ${ }^{1,2}$ iD \\ 1 Instituto Evandro Chagas/SVS/MS, Centro Nacional de Primatas, Ananindeua, Pará, Brasil \\ 2 Universidade Federal do Pará, Instituto de Ciências da Saúde, Laboratório de Neuroplasticidade, Belém, Pará, Brasil
}

\begin{abstract}
Parkinson's disease (PD) is one of the most important research challenges nowadays. In the past five decades, no significant changes in the elucidation of the whole pathophysiology and therapeutic scenario for PD were found, and possible strategies to stop, reverse or cure the disease seem to be on a far horizon. Historically, the most relevant advances in therapeutics for PD were reached using nonhuman primate (NHP) models. They are considered invaluable models for studies on new therapeutic strategies, due to their unquestionable validity to evaluate the efficiency, reliability, and safety for human use. However, NHP species choice may affect research outcomes and must be evaluated with careful consideration of the trade-offs between convenience, costs, scientific relevance, and clinical predictivity. Sapajus apella is a New World monkey species with prominent characteristics as a model for research on the brain and behavior bearing on the human condition, especially regarding the complex features clinically relevant in PD. Among the New World primates, Sapajus apella monkeys more closely resemble humans in several relevant aspects for investigations in PD than other species that are most used for such purposes. This paper discusses the relevance of Sapajus apella monkeys as model to study and develop new therapeutic approaches for PD based on phylogenetic characteristics, telencephalization coefficient, anatomic structures and pathways, genetic features, immune responses, cognitive abilities, and behavioral repertoires.
\end{abstract}

Keywords: Parkinson's Disease; Primates; Cebus; Sapajus apella; Therapy.

\section{RESUMO}

A doença de Parkinson (DP) é um dos desafios de pesquisa mais importantes da atualidade. Nas últimas cinco décadas, não foram observadas mudanças significativas na elucidação da fisiopatologia e no cenário terapêutico da DP, e o desenvolvimento de possíveis estratégias para interromper, reverter ou curar a doença parecem estar em um horizonte distante. Historicamente, os avanços mais relevantes na terapêutica para DP foram alcançados usando modelos primatas não humanos (PNH). Estes são considerados modelos de valor inestimável para estudos de novas estratégias terapêuticas, devido à sua validade indiscutível para avaliar a eficácia, confiabilidade e segurança para uso humano. No entanto, a escolha da espécie de PNH pode afetar os resultados da pesquisa e deve ser avaliada levando em consideração o balanço entre conveniência, custos, relevância científica e previsibilidade clínica. Sapajus apella é uma espécie de macaco do Novo Mundo com características proeminentes como modelo para pesquisas sobre o cérebro e o comportamento relacionados à condição humana, especialmente às características complexas que são clinicamente relevantes na DP. Entre os primatas do Novo Mundo, os macacos Sapajus apella se assemelham mais aos humanos em vários aspectos relevantes para investigações em DP do que outras espécies mais comumente usadas para tais fins. Este artigo discute a relevância dos macacos Sapajus apella como modelo para estudar e desenvolver novas abordagens terapêuticas para DP baseadas em características filogenéticas, coeficiente de telencefalização, estruturas e vias anatômicas, características genéticas, respostas imunológicas, habilidades cognitivas e repertórios comportamentais.

Palavras-chave: Doença de Parkinson; Primatas; Cebus; Sapajus apella; Terapia.

\footnotetext{
Correspondence / Correspondência:

Lane Viana Krejcová

Universidade Federal do Pará, Instituto de Ciências da Saúde

Av. Generalíssimo Deodoro, 01. Bairro: Umarizal. CEP: 66050-160 - Belém, Pará, Brazil

E-mail: lane@ufpa.br / lanekrejcova@gmail.com
} 


\section{INTRODUCTION}

Nonhuman primates (NHP) hold a unique position in biomedical research related to their close phylogenetic proximity to humans. Several NHP species are used in research every year, although they represent only a small proportion of the vertebrate animals used for such purposes. Rodents represent the vast majority of models used in biomedical research, and NHP account for around $0,2 \%$ to $0,5 \% 1,2$. The constant social concern about their use leads to an unremitting reduction of their use, according to the last agreements in Europe and the United States, with the revision of documents, normative and guidelines ${ }^{3}$. Due to ethical considerations, the use of NHP in research is constantly sparing, and results are invaluable given the reduction of their use together with their increased predictive value for the clinical scenario. Consequently, the stress levels and responsibilities carried over by NHP researchers in different fields have been significantly intensified throughout the last decades.

The careful planning of experiments involving NHP raises issues far beyond the experimental design and statistical power. Many other important aspects must be taken into consideration for reaching the most feasible species to answer the proposed questions guaranteeing the best possible translational potential for human clinical advances. Choosing the species for a given investigation demands a thorough analysis, still commonly devoid of careful concern during the experimental planning for several reasons. As large, intelligent, social, long-lived, and non-domesticated animals, NHP are the most challenging species in biomedical research, and issues such as convenience, practical and economic approaches should not be determinant for the choice of the species to be used in a given experiment design; however, characteristics such as phylogenetic position, telencephalization coefficients, morphological, functional, and neurobehavioral aspects should be considered to guarantee the use of the best possible model to answer the intended experimental questions.

Parkinson's disease (PD) is a research challenge in which a model with anatomic structures, pathways, cognitive abilities, and behaviors closer to humans is pivotal to develop novel therapeutic approaches and determine their clinical potential. Historically, the most successful studies in PD, which allowed the comprehension of functional connectivity within the basal ganglia-thalamocortical circuit and provided evidence that the subthalamic nucleus (STN) manipulations could relieve motor symptoms, were performed in monkeys ${ }^{4,5}$. Furthermore, the demonstration that high-frequency electric stimulation of STN led to significant improvement of PD symptoms in monkeys ${ }^{6}$, providing the fundamental underpinning of understanding which paved the way to develop successful surgical therapy for PD, giving rise to subsequent clinical trials ${ }^{7}$ and leading to the most advanced treatment option to PD available nowadays, the deep brain stimulation.

Research with NHP is crucial for discovering new treatments for human diseases, essential for medical progress, and will still be necessary for the foreseeable future?. Their use is highly relevant to the advancement of knowledge with considerable potential benefits to human health. When considering the appropriate model for answering an experimental question, several features will be determinant of to what extent the results can be extrapolated to humans, therefore choosing the most appropriate species is a relevant step for the experimental plan. This paper discusses the use of Sapajus apella monkeys as a model for the investigation of the pathophysiology and the development of novel therapeutic approaches for PD, based on their phylogenetic, neurological, immunological, genetic, and behavioral characteristics.

\section{PARKINSON'S DISEASE AND RESEARCH IN NHP}

Western society has been facing a huge challenge of brain diseases, burgeoning because of our aging population and PD figures as the second most prevalent neurodegenerative disorder ${ }^{8}$. PD is a life-threatening progressive disorder of the nervous system that affects the brain region responsible for initiating voluntary movements. The most common features of PD are tremor, rigidity, bradykinesia, postural instability, and balance and gait disorders, but it also shows a myriad of non-motor symptoms that can be even more disabling than the motor ones ${ }^{9}$. Clinical manifestations of the disease are a consequence of dopamine deficiency resulting from the degeneration of pigmented neurons in the mesencephalic substantia nigra, starting in most patients between the fifth and sixth decades of life. PD affects around 1-2 per 1,000 of the population at any time ${ }^{10}$, and the burden of the disease is very high for the individuals with PD, caregivers, and the health system, with the societal burden per capita around US\$ 6,000 per year ${ }^{11}$. Despite an increase in the arsenal of available treatments and intensive research, the optimum management for this situation remains controversial. Nevertheless, the finest treatment options available for PD are the same for more than five decades, and there were no significant changes in the life expectancy of PD patients for the same period ${ }^{12}$. Furthermore, the pathophysiological and etiological mechanisms and possibilities for early diagnosis are still to be elucidated. Therefore, the development of novel and improved therapeutic options - with prospective to translate efficiently and as soon as possible to clinical practice - is critical to change this scenario.

PD as a complex multisystem disorder represents a research challenge of great proportions, for which most raised questions cannot be fully addressed using cellular, mathematical, or computational models, which precludes the appliance of the ethical principle of replacement. For such purposes, due to the complexity of the neural networks and symptoms to investigate, full organisms having both peripheral and central nervous systems are required. Rodents are the dominant mammalian animal species used in this scenario and have been proven valuable models on the elucidation of several molecular mechanisms, risk factors, and therapeutic approaches. They are inexpensive models, with a short lifespan, easy management, abundant genetic resources, and good reproductive performance 
in captivity, that together with anatomical, physiological, and genetic similarities to humans results on the impact of this model in translational science, however, limited and under permanent discussion ${ }^{13,14,15,16}$.

From a translational medicine standpoint, it is particularly critical to choose appropriate research models because a tremendous amount of money is spent testing drugs and therapies that fail at various stages of pre-clinical and clinical trials. Especially on investigations dedicated to understanding PD, some points on the experimental models become highly relevant for the discussion. As an illustration, although the neuroanatomical substrates underlying motor control are similar for humans and rodents, the behavioral repertoire mediated by those circuits is not. Furthermore, regardless of whether a PD model is based on toxins, lesions or genome modifications, to date, no single rodent model for PD was able to reproduce all key symptoms of the disease ${ }^{17}$.

There are critical differences in the organization of the motor system and behaviors among rodents, $\mathrm{NHP}$, and humans ${ }^{18}$. Namely, major differences in the organization of the corticospinal system include the number of fibers and neural trajectories in motor tracts of primates. They correlate with dexterity and highly developed cortico-motoneuronal projections observed in all dexterous primates that use tools in the wild ${ }^{18,19}$. Such factors can be relevant when investigating a complex neurological condition that affects the motor system such as PD.

Furthermore, as PD shows a myriad of symptoms that includes relevant cognitive and psychiatric changes that may be worsened as adverse effects on pharmacological and surgical treatments ${ }^{20,21}$, the use of NHP in its research greatly enhances the range of behaviors and symptoms that can be studied, helping identify the crucial circuit elements and activity patterns involved in each cluster of symptoms, for which rodent models cannot provide sufficient data for translational needs ${ }^{22,23}$.

It is important to note that refinement does not always lead to the use of a lower species ${ }^{24}$. NHP can be trained for more elaborate tasks than rodents, and essays in NHP are recognized to attain improved predictive value due to their close similarity to humans in genomics ${ }^{1,25}$, neuroanatomic, neurophysiologic 26,27,28, immunogenetic, and age-related dopaminergic changes $22,29,30,31,32$, representing the most relevant model for studies to determine the efficacy and safety of therapeutic approaches to PD.

Among the animal models that have proven effective in predicting the symptomatic efficacy of the antiparkinsonian drugs in current clinical use, the NHP arise as the highest predictive of both therapeutic and adverse effects subsequently observed in clinical trials and almost all known antiparkinsonian medication in current use had the 1-methyl-4-phenyl-1,2,3,6-tetrahyd ropyridine (MPTP) primate as a predictive model of the effects in humans (see table 1 of Duty and Jenner ${ }^{23}$ for reference). Therefore, the parkinsonian NHP remains as a model through which drugs must almost inevitably be tested during the process of selection for clinical trial programs in $\mathrm{PD}^{23}$.

Additionally, the commonalities between human and NHP brains are manifold, and similarities in the cellular composition, encephalization, and structural organization make the primate brain a scaled-down human brain ${ }^{33,34}$. Such similarities include safety-relevant characteristics of the primate immune systems and immunocompetent brain cells, which show relevant differences compared to rodents ${ }^{35,36}$ and can lead to important differences in the effects of several therapeutic approaches over neurons and glial cells. NHP have proven to be the best models for acquiring a closer prediction of human neural and immune responses not only on the pharmacological field but also on more invasive approaches such as implantable biomedical devices, neural grafts, and optogenetics that have shown a high potential for developing new therapeutic approaches for $\mathrm{PD}^{37,38,39}$.

Nevertheless, the NHP PD models also present their own drawbacks. Hitherto, there is no available model that fully recapitulates PD pathological and functional progression, therefore the recent emergence of new animal models based on $\alpha$-synuclein ( $\alpha$-syn) changes has received growing attention ${ }^{40}$. Accumulation of $\alpha$-syn and formation of Lewy bodies are proposed to have a significant role in PD pathology. Like humans, NHP show ubiquitous expression of $\alpha$-syn in the central and peripheral nervous system. The protein sequence and localization are well conserved among mammalian species, with some Old World monkeys displaying an exact copy of the human $\alpha$-syn and New World species showing few altered residues ${ }^{41}$. However, there are no reports of spontaneous PD in NHP and no post-mortem Lewy bodies identification in any NHP PD model ${ }^{22}$, even in marmosets that naturally carry the A53T $\alpha$-syn gene mutation, which in humans is associated with aggressive early-onset PD ${ }^{40,41}$. Therefore, a better understanding of $\alpha$-syn changes in NHP models of PD may help elucidate its role in PD pathology and progression and unravel the obscure genetic basis for major differences in brain aging between humans and NHP.

Several reports have outlined the scientific case for continued use of NHP in biomedical research pointing to neuroscience as an area where the evidence supports their use due to the high relevance of the amount and precision of data that can be collected, and the potential to promote the translation of basic science into clinical practice to improve neurorehabilitation ${ }^{42}$. Recital 17 of European Union Directive 2010/63 states that "the use of NHPs in scientific procedures is still necessary on biomedical research", and that "the use of NHPs should be permitted only in those biomedical areas essential for the benefit of human beings, for which no other alternative replacement methods are yet available ${ }^{\prime \prime 3}$. Therefore, NHP should be used only in those areas that are likely to be of ultimate benefit for humans. Neuroscientific research on PD is one example in which NHP can help us obtain insights into the mechanisms and neural basis of several symptoms, allowing us to investigate new therapeutic strategies and, besides that, provide an indispensable tool for basic research. 


\section{NHP SPECIES AND SCIENTIFIC INVESTIGATIONS IN PD}

Testing potential therapies for PD requires an animal model that simulates the conditions of human disease as closely as possible. NHP have a highly developed nervous system with the same anatomic structures and pathways as humans, and, due to the close phylogenetic relationship, parkinsonian NHP models show similar symptoms, making them the best currently available animal models for PD in the preclinical context ${ }^{44}$.

Research using NHP models for studying PD has been developed in several different species including all four superfamilies of primates, and a great diversity of primate species is observed in neuroscience research. In many cases, however, the species of choice is based on practical reasons given that research with NHP has become increasingly difficult to sustain in many countries ${ }^{45}$. Regardless of that, the most important characteristics to be considered for choosing which NHP species to use in neuroscientific experiments should include the phylogenetic characteristics, telencephalization coefficients, neuroanatomic structures and pathways, cognitive abilities, and behavioral repertoires getting to the model with closer similarities to the human case under investigation, which is indispensable to realistically determine the clinical potential of the possible observed results.

However, only in very few studies we can find the rationale on the phylogenetic similarities or behavioral, neurophysiological or morphological features considered for the choice of the species. Practical aspects may influence the choices, such as animal lifespan and reproductive performance, with a reduction in the use of some species due to inability to keep pace of the production with the research demands in self-sustaining NHP research sources ${ }^{46}$. Also, accelerated efforts to reduce and replace the use of NHP with alternative research models led to severe restrictions to use the most close-related NHP species to humans in research such as the great apes. In consequence, Old World monkeys, which were the most commonly superfamily used in research, has been constantly replaced by New World primate species ${ }^{45}$.

Traditionally, the most used species in PD research is the common marmoset (Callithrix jacchus), a New World monkey native to east-central Brazil. Research using marmosets has grown exponentially in the last decade, due to several practical reasons, such as their small size, fast growth, sophisticated social life, and easy management in captivity. Marmosets mature and age more quickly than bigger monkeys, speeding up studies of diseases that affect development and aging. Also, they give birth twice a year aiding multigeneration genetic experiments. They have recently been genetically engineered to make their brains easier to image and to serve as models for several neurological disorders ${ }^{47}$. Though, there are important factors to be considered about their use that advocate in favor of the use of other bigger NHP species, especially concerning PD therapeutic approaches as a target for investigation. The marmoset characteristics that make them attractive as experimental subjects, such as their rapid development and short lifespan, are what differ them from humans, while bigger NHP species more closely resemble humans ${ }^{48}$.

In this scenario, capuchin monkeys (Sapajus apella) represent an interesting species for investigations in PD. They share several important characteristics of development and aging with humans, and neuroanatomic features with special interest for PD such as age-related changes in basal ganglia structures ${ }^{49}$ that together with cognitive abilities, motor, and behavioral repertoire make them important comparative models for understanding age-related changes and neurodegenerative conditions. Table 1 provides a comparative overview of many research-related relevant characteristics of capuchin monkeys and marmosets.

\section{THE SAPAJUS APELLA AS A MODEL FOR STUDYING PD}

Traditionally, capuchin monkeys have been lumped into the genus Cebus ${ }^{51}$ with four species, Cebus albifrons, Cebus olivaceus, Cebus capucinus, and Cebus apella, and these designations remained for decades. The genus has a large area of occurrence, from the north of Colombia to the south of Argentina, from the Coastal Plain Atlantic to the Andes mountains, distributing geographically throughout most of Brazil, especially in tropical forests spread both to north of the south of the Brazilian Legal Amazonia and in the Cerrado52. More recent shreds of evidence from morphological, phylogenetic, and biogeographic studies have shown that capuchin monkeys are diversified in two clades distinct enough to give rise to two genera: the gracile (untufted) capuchins, which represent the genus Cebus, and the robust (tufted) capuchins, representing the genus Sapajus ${ }^{53}$.

The Sapajus apella, also known as brown capuchin, is a New World primate from the genus Sapajus of the Cebidae family, living in South America, endemic to the Amazonian region, and represents one of the most widespread primates in the Neotropics ${ }^{54,55}$. It is a non-endangered species and shows good reproductive performance in captivity, being one of the species that most easily adapt to human contact. Because of its high reproductive potential and habitat flexibility, it was not devastated by hunting and habitat destruction as observed in other species of primates, being the most seen monkey in Amazonia ${ }^{56}$.

Sapajus apella monkeys have a long life expectancy, a high encephalization rate, and a great tendency toward exploitation and manipulation; they share food, follow an omnivorous diet, and have complex social behaviors such as cooperation and coalition formation ${ }^{57}$. They are also notably pro-social and exhibit social cognitive abilities, such as imitation, that are rare outside the apes. Also, they are the only New World monkey species that show the use of tools on the natural environment, and the variety of tool-tasks in which capuchins are successful together with their complex manipulative abilities are similar to those reported for apes ${ }^{58}$. 
Table 1 - Comparison of some common marmosets (Callithrix jacchus) and capuchin monkeys (Sapajus apella) relevant characteristics as models for investigations in PD

\begin{tabular}{|c|c|c|}
\hline & Callithrix jacchus & Sapajus apella \\
\hline \multirow{8}{*}{ 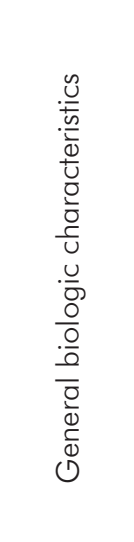 } & Small body size $(\sim 400 \mathrm{~g})$ & Larger body size $(\sim 4 \mathrm{~kg})$ \\
\hline & Rapid development ( 12-15 months to sexual maturity) & Slower development ( $\sim 5-7$ years to sexual maturity) \\
\hline & Old age reached early ( $~ 8$ years) & * \\
\hline & $\begin{array}{c}\text { Short-lived ( } \sim 5-7 \text { years in captivity, with a maximum of } \\
16-17 \text { years) }\end{array}$ & Longer-lived (40-50 years in captivity) \\
\hline & Twin births are common & Single births are common \\
\hline & Shorter gestation ( $\sim 4-5$ months) & Longer gestation (6 months) \\
\hline & Shorter inter-litter interval ( $\sim 5-7$ months) & Longer inter-litter interval ( $\sim 21-24$ months) \\
\hline & Greater phylogenetic distance to humans & Smaller phylogenetic distance to humans \\
\hline \multirow{3}{*}{ 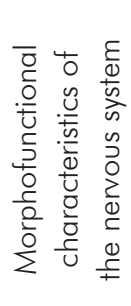 } & $\begin{array}{l}\text { Absolutely and relatively small unconvoluted brains } \\
\text { (among the smallest relative to body size) }\end{array}$ & Absolutely and relatively larger convoluted brains \\
\hline & Higher-order parietal, temporal, and prefrontal areas & Higher-order parietal, temporal, and prefrontal areas \\
\hline & $\begin{array}{l}\text { Lack of monosynaptic projections of corticospinal } \\
\text { neurons onto the motor neurons of the spinal cord } \\
\text { ventral horn }\end{array}$ & $\begin{array}{c}\text { Presence of monosynaptic projections of corticospinal } \\
\text { neurons onto the motor neurons of the spinal cord } \\
\text { ventral horn }\end{array}$ \\
\hline \multirow{3}{*}{ 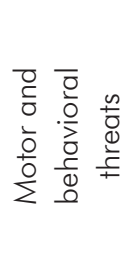 } & $\begin{array}{l}\text { No developed digital opposability and grasping abilities } \\
\text { (grip with the claws) }\end{array}$ & $\begin{array}{l}\text { Well-developed digital opposability and grasping } \\
\text { abilities }\end{array}$ \\
\hline & * & Complex motor planning abilities \\
\hline & No use of tools & $\begin{array}{l}\text { Only new world monkey species that show the use of } \\
\text { tools on the natural environment }\end{array}$ \\
\hline \multirow{2}{*}{ 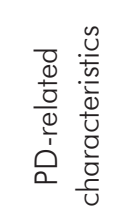 } & Natural A53T mutation in $\alpha$-syn & $\begin{array}{l}\text { Exact human copy of 51-60 amino acid residues of } \\
\qquad \alpha \text {-syn }\end{array}$ \\
\hline & * & $\begin{array}{l}\text { Pattern of development of basal ganglia structures } \\
\text { similar to humans }\end{array}$ \\
\hline
\end{tabular}

Sources: Kishi et al., 201448; Preuss, 201948; Kimberley et al., 201050; Vermilyea and Emborg, 201541; AnAge/The Animal Ageing and Longevity Database (genomics.senescence.info).

* Information not available.

Therefore, the motor, psychologic, and cognitive complexity of the capuchin monkey offers abundant sources for the analysis of different symptomatic and neurophysiological aspects on the course of PD and experimental therapeutic approaches closer to a human perspective. In an evolutionary context, capuchins are the most phylogenetically related to humans among New World primates, based on morphological, behavioral, and genetic characteristics ${ }^{59}$ (Figure 1).

Although hitherto there are no reports of spontaneous PD in NHP, they present age-related dysfunctions of the dopaminergic nigrostriatal system, associated with motor impairments 22 , pointing to a vulnerability to changes that may be related to the development of neurodegenerative diseases during ageing $^{62}$. The New World primates contain some of the short-lived as well as some of the long-lived monkey species, ranging from small species such as marmosets (quick development, relatively short-lived, and plentiful reproduction) to capuchin monkeys, which by contrast have the longest reported captive lifespan of any monkey, only slightly exceeded by the great apes ${ }^{63}$ (Table 1). Due to developmental and cytoarchitectonic patterns similar to humans in the basal ganglia structures ${ }^{49,64}$, the capuchin monkeys may be the most suitable options as models to provide a framework to study PD pathology and therapeutic approaches in an aged system.

The brain morphology in New World monkeys evolved with the occupation of several ecological niches and is strongly associated with the evolutionary increase of social behaviors ${ }^{65}$. The high encephalization rate of Sapajus apella also advocates their genetic proximity to humans, since human-specific genes are responsible for cortical expansion by the promotion of basal progenitor amplification, driving the formation of gyrencephalic cortex, differently from other NHP species such as marmosets that are quite lissencephalic ${ }^{66}$. 


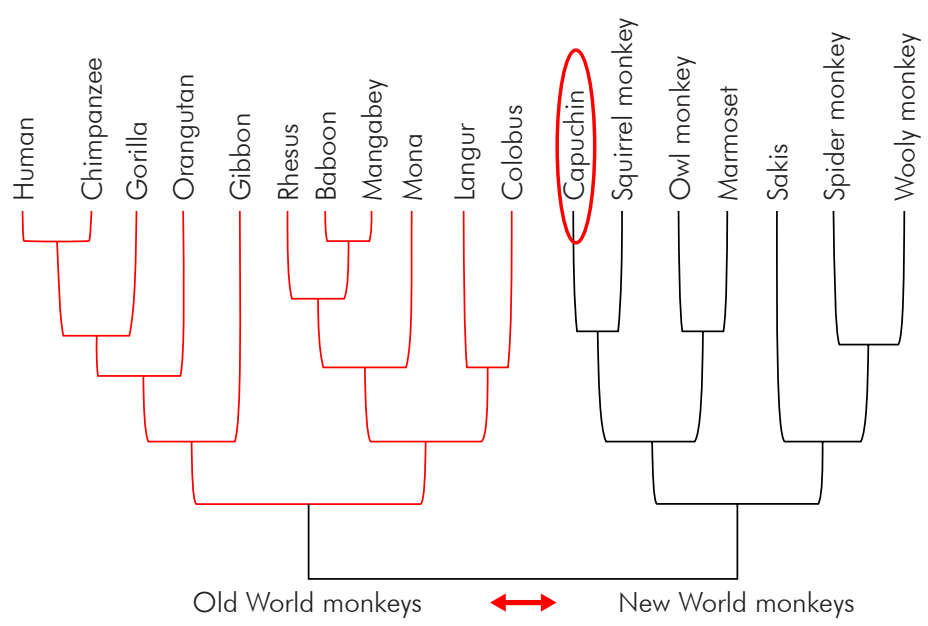

Source: Based on Baum et al., 200559; Chatteriee et al., 200960; and Surridge et al., 200361. Available at EvoEd phylogenetics (https://www.evo-ed.org/ Pages/Primates/phylogenetics.html).

The position of capuchin monkeys is highlighted.

Figure 1 - Rooted phylogenetic representative tree of Old World and New World primate groups based on morphological, behavioral, and genetic characteristics

The diversification of brain morphology comprises one of the most prominent features of the primate adaptive radiation and therefore the evolutionary success, and particularly the convergent brain phenotypes may be related to ecological and behavioral factors that directly interfere with complex abilities such as social complexity 65 and can be reflected also in other range of behaviors as well as an anatomical and functional organization.

It is still unclear if or how the genetic and morphofunctional differences in primate brains interfere on the presentation of pathologic and clinical features in PD. The 6-OHDA and MPTP-based models are the most used experimental NHP models of PD and replicate the human disease regarding neurotransmitter loss, neurochemical, morphological, and behavioral changes, but with lack of presentation of proteinaceous aggregates or typical Lewy bodies, which is one of the cardinal hallmarks of the pathophysiology of $\mathrm{PD}^{67}$. Moreover, even though all primates develop neurochemical and morphologic effects of MPTP and 6-OHDA toxins, the degree of susceptibility is variable among species ${ }^{68}$, and this may be related to changes in the $\alpha$-syn ${ }^{41}$.
Nonetheless, the genetic basis for major differences in brain aging between humans and other primates is as obscure as is the basis for differences in life span. Aging monkeys and humans accumulate deposits of $\alpha$-syn which is ubiquitously expressed in the nervous system of humans and NHP with a well-conserved protein sequence among species ${ }^{41}$. For example, gorillas, orangutans, and bonobos have exact copies of the human protein sequence, and New World NHP have few altered sites of $\alpha$-syn protein sequence compared to humans, with the presence of threonine in the 53rd amino acid location (A53T) naturally occurring in marmosets, which in humans is a missense mutation associated with aggressive and early onset PD. The Sapajus apella monkey, in this aspect, shows the similar human sequence of the residues 51-60 of $\alpha$-syn ${ }^{69}$. For the other side, as the marmosets, Sapajus apella monkeys present a total of four variations in the $\alpha$-syn amino acid sequence compared to humans (Table 2). For marmosets, the alterations are A53T, S87N, Q99H, and $\mathrm{N} 103 \mathrm{~S}^{41}$. For Sapajus apella, the alterations are S87N, K96R, Q99H, and N103S69. The role of such alterations on PD pathology, if present, is still not clear.

Table 2 - $\alpha$-syn amino acid sequence residues 51-60 in different primate species. The $\alpha$-syn amino acid sequence is highly conserved in humans and NHP

\begin{tabular}{|c|c|c|c|c|c|c|c|c|c|c|}
\hline Species & \multicolumn{10}{|c|}{53} \\
\hline Human WT & $G$ & V & A & T & V & A & $E$ & K & $\mathrm{T}$ & K \\
\hline Human A53T & $G$ & V & $T$ & $\mathrm{~T}$ & V & A & $\mathrm{E}$ & K & $\mathrm{T}$ & K \\
\hline Sapajus apella & G & V & A & T & V & A & $\mathrm{E}$ & K & T & K \\
\hline Callithrix jacchus & $G$ & V & T & $\mathrm{T}$ & V & A & $E$ & K & $\mathrm{T}$ & K \\
\hline
\end{tabular}

Source: Vermilyea and Emborg, 201541; and NCBI protein database. Color represents amino acid variation (red) compared to human wild type (WT) sequence (yellow). 
Brains have substantial ecological and adaptive importance because they underlie the behavior that allows an animal to successfully interact with their environment. In this sense, primates constitute a notable example, as the evolution of brain morphology is one of the most prominent features of their diversification ${ }^{70}$. Sapajus apella have relatively large brains and their brain development, as in humans, is widely influenced by the experiences in early childhood. The use of Sapajus apella monkeys may allow a more detailed analysis of PD symptomatology in both motor and non-motor aspects for several reasons and some of them are pointed out below.

\section{MOTOR SKILLS}

From an evolutionary point of view, exquisite manual dexterity is largely considered a prerogative of primates, as other mammalian orders do not exhibit such a high degree of manual dexterity. The Sapajus apella monkeys, as humans and Old World monkeys, show highly advanced manual dexterity, with a precision grip between the thumb and index finger due to the development of direct cortico-motoneuronal connections observed only in higher primates ${ }^{71}$. Since PD comprises several changes affecting global and fine motor coordination in different levels, the observance of the effects of experimental conditions over fine motor coordination skills can bring the analysis to a new level. Marmosets, despite their capacities of pre-shaping hand for grasping objects based on visuomanual coordination, do not present a precision grip, a critical ability for important advances involving fine motor behavior including tool use ${ }^{72}$. Sapajus apella monkeys show a highly developed precision grip, manual dexterity, and complex fine motor skills which, for PD motor studies, can allow a careful investigation beyond the rotational behaviors commonly analysed on rodent and marmoset models of PD, for which the most used motor tasks only evaluate the global motor coordination of large muscular groups ${ }^{73}$. It has been recently reported that Sapajus apella monkeys also present complex motor planning abilities ${ }^{74}$ and are able to modify a behavior to anticipate the future consequences of a given action, which may be related to the presence of multiple premotor areas in the frontal lobe ${ }^{75}$ as well as a proprioceptive cortical area 2 and a well-developed cortical area 5, which is associated with motor planning, visually guided reaching, grasping, and manipulation ${ }^{76}$.

\section{BASAL GANGLIA AND BRAIN DEVELOPMENT}

As observed in humans, the brain development of Sapajus apella is markedly influenced by early life events, with the presentation of brain growth spurt during early childhood ${ }^{77}$, and relatively big brain size after complete development. In the same direction, the capuchin monkey newborn, like all primates, is considered a relatively early mammal, and they show altricial behavior ${ }^{78}$. The high rate of brain development after birth leads to significant individual behavioral diversification as observed in humans ${ }^{79}$, and they show well-developed social intelligence compared to other platyrrhines primate species ${ }^{80}$.
Outputs of basal ganglia structures are not only involved in planning, initiation, and regulation of movement, but also in a variety of non-motor and cognitive functions such as working memory, visual perception, and attention switching. Basal ganglia are involved in both complex cognitive and motor acts, and imaging studies have revealed a similar pattern of development of basal ganglia structures similar to humans in capuchin monkeys, notably the Sapajus apella lineage, suggesting them as a suitable model for studying neurodevelopmental and age-related disorders ${ }^{49}$.

\section{NON-MOTOR SKILLS}

Unlike what is observed in simpler models such as rodents, primates exhibit intricate cognitive processes, complex social interactions, and a diverse behavioral repertoire, therefore they are more susceptible to behavioral, psychiatric, and psychological disorders ${ }^{81}$. Sapajus apella monkeys, as other primates, share with human core features of brain architecture and function, and complex social and cognitive behaviors typical of the primate order ${ }^{82}$. Many behavioral aspects of Sapajus apella point that this species can be particularly promising as a model for studying the neural circuits disturbances in PD and their behavioral and cognitive consequences. Sapajus apella presents social behavior and cognition features more similar to humans in several aspects, such as stable social relationships, dynamic social structure, and maintenance of affiliative relationships with cooperation in various ways ${ }^{83}$.

When it comes to studying cognitive processes and other complex behaviors, some procedures you can only perform with a primate model, for rodents do not present the complex psychological and behavioral features that are intertwined and mutually influenced by the disruption of dopaminergic systems that occur in PD. Sapajus apella cognitive task performance and personality evolved in behavioral and cognitive traits qualitatively similar to those of great apes, and individual differences in behavior and cognition often reflect personality differences ${ }^{82}$. Analyzing PD symptomatic profiles in such models can provide outcomes that might lead to new scientific and therapeutic approaches to PD. Recent studies are pointing to promising therapeutic approaches such as stem cell-based replacement therapies for which investigations using NHP have played an instrumental role in the process of preclinical optimization to guarantee safety and efficacy and facilitate the translation for humans $27,39,84$.

\section{CONCLUSION}

There are some complex and clinically relevant aspects of the symptomatology of Parkinson's disease that simply cannot be investigated with simple experimental models such as rodents in a relevant way to human patients. It is important to note that the appropriateness of each model and species for the development and assessment of treatments or basic science investigations depends on several factors, including the experimental 
aim of the study and whether the emphasis is placed on the analysis of behavioral, cognitive, and fine motor deficits, for which larger and more complex species are better to bridge the gap between rodent studies and clinical applications. Primates present ethical and practical challenges as animal models; however, NHP seem to be inevitable models for acquiring a closer prediction of human neural and immune responses due to their highly developed neural systems that base the cluster of symptoms observed in PD, together with safety-relevant differences between rodent and primate immune systems that can influence the outcomes of novel therapeutic strategies.

Sapajus apella monkey is a very promising NHP model for research on PD, for its complex behavioral and motor repertoire, and cognitive abilities, together with the neuroanatomical similarities of basal ganglia structural organization and age-related changes to humans, pointing that they comprise very suitable models for the study of new therapeutic approaches for
PD. Their appropriate use as experimental models for PD might help elucidate several mechanisms of the disease and help to bridge the gap between rodent studies and clinical applications.

\section{FINANCIAL SUPPORT}

This study received funding from the European Union's Horizon 2020 Research and Innovation Program under contract No. 767092.

\section{AUTHORS CONTRIBUTION}

JACP Muniz and LV Krejcová conceived and designed the study; LCP Leal collected the data. JACP Muniz; LCP Leal and CP Bahia contributed on data analysis; LV Krejcová wrote the paper; and JACP Muniz, LCP Leal, and CP Bahia proofread the manuscript.

\section{CONFLICTS OF INTEREST}

The authors confirm that there are no known conflicts of interest associated with this publication.

\section{REFERENCES}

1 Phillips KA, Bales KL, Capitanio JP, Conley A, Czoty PW, 't Hart BA, et al. Why primate models matter. Am J Primatol. 2014 Sep;76(9):801-27.

2 Annual statistics of scientific procedures on living animals, Great Britain 2019. London: Stationery Office; 2020.

3 Louhimies S. Directive 86/609/EEC on the protection of animals used for experimental and other scientific purposes. Altern Lab Anim. 2002 Dec;30 Suppl 2:217-9.

4 Bergman $H$, Wichmann T, DeLong MR. Reversal of experimental parkinsonism by lesions of the subthalamic nucleus. Science. 1990 Sep;249(4975):1436-8.

5 Aziz TZ, Peggs D, Sambrook MA, Crossman AR. Lesion of the subthalamic nucleus for the alleviation of 1-methyl-4-phenyl-1,2,3,6-tetrahydropyridine (MPTP)-induced parkinsonism in the primate. Mov Disord. $1991 ; 6(4): 288-92$.

6 Benazzouz A, Gross C, Féger J, Boraud T, Bioulac B. Reversal of rigidity and improvement in motor performance by subthalamic high-frequency stimulation in MPTP-treated monkeys. Eur J Neurosci. 1993 Apr;5(4):382-9.

7 Limousin P, Pollak P, Benazzouz A, Hoffmann D, Le Bas JF, JE Perret, et al. Effect on parkinsonian signs and symptoms of bilateral subthalamic nucleus stimulation. Lancet. 1995 Jan;345(8942):91-5.

8 de Lau LM, Breteler MM. Epidemiology of Parkinson's disease. Lancet Neurol. 2006 Jun;5(6):525-35.
9 Chaudhuri KR, Schapira AHV. Non-motor symptoms of Parkinson's disease: dopaminergic pathophysiology and treatment. Lancet Neurol. 2009 May;8(5):464-74.

10 Tysnes OB, Storstein A. Epidemiology of Parkinson's disease. J Neural Transm (Vienna). 2017 Aug;124(8):901-5.

11 Whetten-Goldstein K, Sloan F, Kulas E, Cutson T, Schenkman M. The burden of Parkinson's disease on society, family, and the individual. J Am Geriatr Soc. 1997 Jul;45(7):844-9

12 Racette BA, Willis AW. Time to change the blind men and the elephant approach to Parkinson disease? Neurology. 2015 Jul;85(2):190-6.

13 Aitman T, Dhillon P, Geurts AM. A RATional choice for translational research? Dis Model Mech. 2016 Oct;9(10): 1069-72.

14 Gennaro M, Mattiello A, Pizzorusso T. Rodent models of developmental ischemic stroke for translational research: strengths and weaknesses. Neural Plast. 2019 Apr;2019:5089321.

15 Montenegro MF, Sundqvist ML, Nihlén C, Hezel $M$, Carlström M, Weitzberg $E$, et al. Profound differences between humans and rodents in the ability to concentrate salivary nitrate: implications for translational research. Redox Biol. 2016 Dec;10:206-10.

16 Freeman SM, Young LJ. Comparative perspectives on oxytocin and vasopressin receptor research in rodents and primates: translational implications. J Neuroendocrinol. 2016 Apr;28(4).

17 Terzioglu M, Galter D. Parkinson's disease: genetic versus toxin-induced rodent models. FEBS J. 2008 Feb;275(7):1384-91 
18 Courtine G, Bunge MB, Fawcett JW, Grossman RG, Kaas $J H$, Lemon $R$, et al. Can experiments in nonhuman primates expedite the translation of treatments for spinal cord injury in humans? Nat Med. 2007 May;13(5):561-6.

19 Lemon RN. Descending pathways in motor control. Annu Rev Neurosci. 2008;31:195-218.

20 Swainson R, Rogers RD, Sahakian BJ, Summers BA, Polkey CE, Robbins TW. Probabilistic learning and reversal deficits in patients with Parkinson's disease or frontal or temporal lobe lesions: possible adverse effects of dopaminergic medication. Neuropsychologia. 2000;38(5):596-612.

21 Bronstein JM, Tagliati M, Alterman RL, Lozano AM, Volkmann J, Stefani A, et al. Deep brain stimulation for Parkinson disease: an expert consensus and review of key issues. Arch Neurol. $2011 ; 68(2): 165$.

22 Emborg ME. Nonhuman primate models of Parkinson's disease. Ilar J. 2007;48(4):339-55.

23 Duty S, Jenner P. Animal models of Parkinson's disease: a source of novel treatments and clues to the cause of the disease. $\mathrm{Br} J$ Pharmacol. 2011 Oct;164(4):1357-91.

24 Institute of Medicine (US), National Research Council (US). International animal research regulations: impact on neuroscience research: workshop summary. Washington: National Academies Press; 2012.

25 Harding JD. Progress in genetics and genomics of nonhuman primates. Ilar J. 2013;54(2):77-81.

26 Passingham R. How good is the macaque monkey model of the human brain? Curr Opin Neurobiol. 2009 Feb; 19(1):6-11.

27 Grow DA, McCarrey JR, Navara CS. Advantages of nonhuman primates as preclinical models for evaluating stem cell-based therapies for Parkinson's disease. Stem Cell Res. 2016 Sep;17(2):352-66.

28 Vermilyea SC, Emborg ME. The role of nonhuman primate models in the development of cell-based therapies for Parkinson's disease. J Neural Transm. 2018;125:365-84.

29 Collier TJ, Lipton J, Daley BF, Palfi S, Chu Y, Sortwell $C$, et al. Aging-related changes in the nigrostriatal dopamine system and the response to MPTP in nonhuman primates: diminished compensatory mechanisms as a prelude to parkinsonism. Neurobiol Dis. 2007 Apr;26(1):56-65.

30 Arnsten AF, Cai JX, Steere JC, Goldman-Rakic PS. Dopamine D2 receptor mechanisms contribute to age-related cognitive decline: the effects of quinpirole on memory and motor performance in monkeys. J Neurosci. 1995 May; 15(5 Pt 1):3429-39.
31 Kanaan NM, Kordower JH, Collier TJ. Age-related accumulation of Marinesco bodies and lipofuscin in rhesus monkey midbrain dopamine neurons: relevance to selective neuronal vulnerability. J Comp Neurol. 2007 Jun;502(5):683-700.

32 Siddiqi ZA, Peters A. The effect of aging on pars compacta of the substantia nigra in rhesus monkey. J Neuropathol Exp Neurol. 1999 Sep;58(9):903-20.

33 Herculano-Houzel S. The human brain in numbers: a linearly scaled-up primate brain. Front Hum Neurosci. 2009 Nov;3:31.

34 Azevedo FAC, Carvalho LRB, Grinberg LT, Farfel $J M$, Ferretti REL, Leite REP, et al. Equal numbers of neuronal and nonneuronal cells make the human brain an isometrically scaled-up primate brain. J Comp Neurol. 2009 Apr;513(5):532-41.

35 Mestas J, Hughes CCW. Of mice and not men: differences between mouse and human immunology. J Immunol. 2004 Mar;1 72(5):2731-8.

36 Zschaler J, Schlorke D, Arnhold J. Differences in innate immune response between man and mouse. Crit Rev Immunol. 2014;34(5):433-54.

37 Delbeke J, Hoffman L, Mols K, Braeken D, Prodanov D. And then there was light: perspectives of optogenetics for deep brain stimulation and neuromodulation. Front Neurosci. 2017 Dec; 1 1:663.

38 DiMauro TM, Attawia M, Holy C, Lilienfeld S, Sutton JK, Ward M, inventors; DePuy Synthes Products, Inc., assignee. Red light implant for treating Parkinson's disease. United States patent US 7,288, 108. 2005 Mar 14.

39 Chen ZZ, Niu YY. Stem cell therapy for Parkinson's disease using non-human primate models. Zool Res. 2019 Sep;40(5):349-57.

40 Marmion DJ, Kordower JH. $\alpha$-Synuclein nonhuman primate models of Parkinson's disease. J Neural Transm (Vienna). 2018 Mar;125(3):385-400.

41 Vermilyea SC, Emborg ME. $\alpha$-Synuclein and nonhuman primate models of Parkinson's disease. J Neurosci Methods. 2015 Nov;255:38-51.

42 Weatherall D. The Weatherall report on the use of non-human primates in research. London: Royal Society; 2006. p. 1-145.

43 Olsson IAS, Silva SP, Townend D, Sandøe P. Protecting animals and enabling research in the European Union: an overview of development and implementation of directive 2010/63/EU. Ilar J. 2016 May;57(3):347-57.

44 Badin RA, Vadori M, Cozzi E, Hantraye P. Translational research for Parkinson's disease: the value of pre-clinical primate models. Eur J Pharmacol. 2015 Jul;759:118-26. 
45 Carlsson HE, Schapiro SJ, Farah I, Hau J. Use of primates in research: a global overview. Am J Primatol. 2004 Aug;63(4):225-37.

46 Cohen J. Vaccine studies stymied by shortage of animals. Science. 2000 Feb;287(5455):959-60.

47 Kishi N, Sato K, Sasaki E, Okano H. Common marmoset as a new model animal for neuroscience research and genome editing technology. Dev Growth Differ. 2014 Jan;56(1):53-62.

48 Preuss TM. Critique of pure marmoset. Brain Behav Evol. 2019;93(2-3):92-107.

49 Phillips KA, Sobieski CA, Gilbert VR, Chiappini-Williamson C, Sherwood CC, Strick $\mathrm{PL}$. The development of the basal ganglia in capuchin monkeys (Cebus apella). Brain Res. 2010 May; 1329:82-8.

50 Kimberley TJ, Samargia S, Moore LG, Shakya JK, Lang CE. Comparison of amounts and types of practice during rehabilitation for traumatic brain injury and stroke. J Rehabil Res Dev. 2010;47(9):851-62.

51 Silva Jr JS. Taxonomy of capuchin monkeys, Cebus erxleben, 1777. Neotrop Primates. 2002;10(1):29.

52 Auricchio P. Primatas do Brasil. São Paulo: Terra Brasilis; 1995.

53 Alfaro JWL, Silva Jr JS, Rylands AB. How different are robust and gracile capuchin monkeys? An argument for the use of Sapajus and Cebus. Am J Primatol. 2012 Apr;74(4):273-86.

54 Alfaro JWL, Boubli JP, Olson LE, Di Fiore A, Wilson B, Gutiérrez-Espeleta GA, et al. Explosive pleistocene range expansion leads to widespread Amazonian sympatry between robust and gracile capuchin monkeys. J Biogeogr. 2012;39(2):272-88.

55 Wilson DE, Reeder DM, editors. Mammal species of the world: a taxonomic and geographic reference. 3rd ed. Baltimore: Johns Hopkins University Press; 2005.

56 Rylands AB, Mittermeier RA, Rodriguez-Luna E. Conservation of neotropical primates: threatened species and an analysis of primate diversity by country and region. Folia Primatol (Basel). 1997;68(3-5):134-60.

57 Fragaszy DM, Visalberghi E, Fedigan LM. The complete capuchin: the biology of the genus Cebus. Cambridge (UK): Cambridge University Press; 2004. p. 36-54.

58 Visalberghi E. Capuchin monkeys: a window into tool use in apes and humans. In: Gibson KR, Ingold $T$, editors. Tools, language and cognition in human evolution. Cambridge (UK): Cambridge University Press; 1993. p. 138-50.

59 Baum DA, Smith SD, Donovan SSS. The tree-thinking challenge. Science. 2005 Nov;310(5750):979-80.
60 Chatteriee HJ, Ho SYW, Barnes I, Groves C. Estimating the phylogeny and divergence times of primates using a supermatrix approach. BMC Evol Biol. 2009 Oct;9:259.

61 Surridge AK, Osorio D, Mundy NI. Evolution and selection of trichromatic vision in primates. Trends Ecol Evol. 2003 Apr; 18(4): 198-205.

62 Finch CE, Austad SN. Primate aging in the mammalian scheme: the puzzle of extreme variation in brain aging. Age. 2012 Oct;34(5):1075-91.

63 Judge DS, Carey JR. Postreproductive life predicted by primate patterns. J Gerontol A Biol Sci Med Sci. 2000 Apr;55(4):B201-9.

64 Middleton FA, Strick PL. Basal-ganglia 'projections' to the prefrontal cortex of the primate. Cereb Cortex. 2002 Sep;12(9):926-35.

65 Aristide L, Reis SF, Machado AC, Lima I, Lopes RT, Perez SI. Brain shape convergence in the adaptive radiation of New World monkeys. Proc Natl Acad Sci USA. 2016 Feb; 113(8):2158-63.

66 Florio M, Albert M, Taverna E, Namba T, Brandl H, Lewitus $E$, et al. Human-specific gene ARHGAP1 $1 B$ promotes basal progenitor amplification and neocortex expansion. Science. 2015 Mar;347(6229): 1465-70.

67 Konnova EA, Swanberg M. Animal models of Parkinson's disease. In: Stoker TB, Greenland JC, editors. Parkinson's disease: pathogenesis and clinical aspects. Brisbane (AU): Codon; 2018. Chapter 5; p. 83-106.

68 Tolwani RJ, Jakowec MW, Petzinger GM, Green S, Waggie K. Experimental models of Parkinson's disease: insights from many models. Lab Anim Sci. 1999 Aug;49(4):363-71.

69 Geer LY, Marchler-Baver A, Geer RC, Han L, He J, $\mathrm{He} \mathrm{S}$, et al. The NCBI bioSystems database. Nucleic Acids Res. 2010 Jan;38 Suppl 1:D492-6.

70 Barton RA. Primate brain evolution: integrating comparative, neurophysiological, and ethological data. Evol Anthropol. 2006 Nov-Dec;15(6):224-36.

71 Bortoff GA, Strick PL. Corticospinal terminations in two new-world primates: further evidence that corticomotoneuronal connections provide part of the neural substrate for manual dexterity. J Neurosci. 1993 Dec;13(12):5105-18.

72 Marzke MW. Precision grips, hand morphology, and tools. Am J Phys Anthropol.1997 Jan; 102(1):91-110.

73 Philippens IH, Melchers BP, Roeling TA, Bruijnzeel PL. Behavioral test systems in marmoset monkeys. Behav Res Methods Instrum Comput. 2000 Feb;32(1):173-9.

74 Zander SL, Judge PG. Brown capuchin monkeys (Sapajus apella) plan their movements on a grasping task. J Comp Psychol. 2015 May;129(2):181-8. 
75 Dum RP, Strick PL. Frontal lobe inputs to the digit representations of the motor areas on the lateral surface of the hemisphere. J Neurosci. 2005 Feb;25(6):1375-86.

76 Padberg J, Franca JG, Cooke DF, Soares JGM, Rosa MGP, Fiorani Jr M, et al. Parallel evolution of cortical areas involved in skilled hand use. J Neurosci. 2007 Sep;27(38):10106-15.

77 Fragaszy DM, Visalberghi E, Fedigan LM. The complete capuchin: the biology of the genus Cebus. New York: Cambridge University Press; 2004.

78 Portmann A. A zoologist looks at humankind. New York: Columbia University Press; 1990.

79 Elman JL, Bates EA, Johnson MH, Karmiloff-Smith A, Parisi D, Plunkett K. Rethinking innateness: a connectionist perspective on development. Cambridge (MA): MIT Press; 1996.

80 Perry S, Barrett HC, Manson JH. White-faced capuchin monkeys show triadic awareness in their choice of allies. Anim Behav. 2004 Jan;67(1):165-70.
81 Lutz CK. Stereotypic behavior in nonhuman primates as a model for the human condition. llar J. 2014;55(2):284-96.

82 Morton FB, Lee PC, Buchanan-Smith HM, Brosnan SF, Thierry B, Paukner A, et al. Personality structure in brown capuchin monkeys (Sapajus apella): comparisons with chimpanzees (Pan troglodytes), orangutans (Pongo spp.), and rhesus macaques (Macaca mulatta). J Comp Psychol. 2013 Aug; 127(3):282-98.

83 Mauro PI. Análise da estrutura social de um grupo de macacos-prego (Cebus apella) em condições de semi-cativeiro [dissertação]. São Paulo (SP): Universidade de São Paulo, Instituto de Psicologia; 1994.

84 Wang YK, Zhu WW, Wu MH, Wu YH, Liu ZX, Liang $L M$, et al. Human clinical-grade parthenogenetic ESC-derived dopaminergic neurons recover locomotive defects of nonhuman primate models of Parkinson's disease. Stem Cell Reports. 2018 Jul $10 ; 11(1): 171-82$. 